Summer July 1, 2015

\title{
Sample Size Effect on Combustion Analysis
}

Osueke C. O

Uguru Okorie Daniel

Aondoyila Kuhe 


\title{
Sample Size Effect on Combustion Analysis
}

\author{
Osueke C. $\mathbf{O}^{1}$., Uguru-Okorie Daniel ${ }^{2} *$, Aondoyila Kuhe ${ }^{3}$. \\ ${ }^{1,2}$ The Department of Mechanical Engineering, Landmark University, Omu Aran, Kwara State, Nigeria. \\ ${ }^{3}$ University of Agriculture Makurdi, Department of Mechanical Engineering. \\ *Correspondence: danchukus@yahoo.com
}

\begin{abstract}
Engine parameters vary from one cycle to the other and this makes engine analysis with data from a single working cycle insufficient in capturing or modelling an engine behaviour. The variation observed in engine has necessitated the use sample sizes of data obtained during an engine operation to obtain results that are representative of the engine being investigated. Research has shown that the use of very large data sample size increases the storage needed and processing time and does not necessary give better results over results obtained with lesser sample sizes. The number of sample size to use for analysis remains a subject of debate and investigation with researchers proposing the use of varying sample sizes for combustion analysis in engines. There is a need for the selection of an optimum sample size for engine analysis.
\end{abstract}

Engine data were obtained from a spark ignition engine which operated on gasoline and varying degree of blend of gasoline and biofuel. The effects of the use of sample sizes of 20, 40, 60 and 100 on the result of the analysis were determined. The percentage difference and the mean percentage difference for each of the sample sizes tested relative to the maximum available sample size were determined too.

Based on results from the analysis, it was suggested that sample sizes that gave mean percentage difference values within the range \pm 1.5 relative to the maximum available samples size are appropriate for use in combustion analysis in engines.

Keywords: Analysis, Combustion, Engine, Fuel, Sample Size.

\subsection{INTRODUCTION}

Combustion in spark ignition engines occurs by the introduction of spark from the ignition system through the spark plug. Experimental data from engine research have shown that over an engine operating cycle, experimental data obtained from cycle to cycle vary (Aghdam et. al., 2007 and Conway, 2013).

The variation in engine operating parameter from one cycle to the other makes the analysis of engine combustion parameter with data from a single working cycle insufficient in capturing or modelling engine behaviour. The number of engine cycle data required for processing, to capture average parameters of an engine is still being debated by researchers and is an important issue in combustion analysis. Combustion parameters vary from one cycle to the other over an engine operating cycle
(Hussin, 2012). The required/optimum sample size of data required for analysis still remains a subject of debate. While some researchers have used data sample size of below forty (40), some have used hundred (100) and above data sample size. Some researchers have suggested better accuracy in analysis of result with increase in number of sample size used (Chang, 2002).

\subsection{JUSTIFICATION}

Research has shown that the use of very large data sample size increases the storage needed and processing time and does not necessary give better results over results obtained with lesser sample sizes. There is a need for the selection of an optimum sample size for engine analysis.

\subsection{EFFECT OF NUMBER OF CYCLES ON COMBUSTION PARAMETER RESULTS}

Variation in combustion parameters in engines varies from one engine cycle to the other and this has been debated by researchers over the years with the aim of adopting the number of data required for analysis to get results that are representative of the mean engine condition.

Based on the research carried out by Cartwright and Fleck (1996) in a two-stroke engine at wide open throttle (WOT) condition, between thirty five (35) and forty (40) engine cycle data were suggested for engine performance analysis. Lancaster et. al. (1975) suggested 40 cycles and for highly variability conditions, 300 cycles. Chun and Heywood (1987) used 39 cycles for processing and comparison of mass fraction of mixture burned and heat release estimate. 44 cycles were used by Gatowskii et. al. (1984) in engine performance analysis.

Brown (2009) stated that at a minimum of fifty (50) number of cycles, a stable value for engine test is attained and stated that a further increase in the number of cycles for calculation makes no significant change in the engine results. He used 50 cycles for the determination of the coefficient of variation for the indicated mean effective pressure $\left(\mathrm{COV}_{\mathrm{IMEP}}\right)$ for the engine under study. He suggested for large fluctuations at least 200 cycles are needed. Fifty (50) pressure data cycles, were used by Jensen and Schramm (2000) in the three-zone heat release analysis. Hussin (2012) carriedout a PIV experiment to study the in-cylinder turbulent flow in the engine cylinder and suggested 300, 400, 500 and 600 number of cycles for engine speeds of 750, 1000, 1250 and $1500 \mathrm{rpm}$. He further compared results gotten with 50 and 400 number of cycles and got a $2.7 \%$ difference in the longitudinal length scale of the flow in $\mathrm{X}$ direction. With the a consideration of the large data and time 
storage requirement, he suggested that 50 cycles was considered a relatively acceptable solution.

For statistical validation of a one-zone burn-rate analysis, Cheung and Heywood (1993) recommended the use of more than 100 cycles. Hayes et. al. Noted that in most heat release programs, between 100 to 300 cycles were used by researchers. The effect of number of cycles used on the result of an engine's indicated mean effective pressure (IMEP) result obtained was investigated by Burnt and Emtage (1996). Burnt and Emtage (1996), foundout that an increase of the number of cycle to use to 100 cycles, gave less than $1 \%$ error of IMEP and they reported that they was no considerable difference in result for an increase in the cycle number from 100 to 300 cycles and finally 150 cycles was recommended for analysis.

\subsection{COMBUSTION PARAMETERS}

\subsubsection{Mean Effective Pressure}

The pressure data obtained during an engine cycle can be used to calculate the work transfer from the expanding combusting mixture of air and fuel in the combustion chamber to the engine piston. Mean Effective Pressure (MEP) being a measure of an engine capacity to do work, is independent of the engine displacement.

Mean Effective Pressure (MEP) quantity can be divided into three types (Heywood, 1988):-

$>$ Indicated Mean Effective Pressure (IMEP)

$>$ Brake Mean Effective Pressure (BMEP)

$>$ Friction Mean Effective Pressure (FMEP)

\subsubsection{Indicated Work per Cycle}

Indicated work per cycle is the summation of work done in an engine cycle. In engine combustion analysis, indicated work per cycle $\left(\mathrm{W}_{\mathrm{c}, \mathrm{i}}\right)$; is obtained by the numerical integration of the cylinder pressure and cylinder volume (PVdiagram) curve of the engine cycle.

$$
\mathrm{W}_{\mathrm{c}, \mathrm{i}}=\oint P d V
$$

The Indicated Work obtained from an engine cycle could be expressed as: gross indicated work, net indicated work or pumping indicated work. This depends on the method of calculation Heywood (1988) and Brown (2009).

The Gross Indicated Work per cycle $\left(\mathrm{W}_{\mathrm{g}, \mathrm{i}}\right)$ : This is the work delivered to the piston over the compression and expansion strokes (i.e. when the inlet valves/ports and exhaust valves/ports are closed in the 4 and 2 stroke engines).

$$
\mathrm{W}_{\mathrm{g}, \mathrm{i}}=\int_{I P C}^{E P O} P d V
$$

Net Indicated Work per cycle $\left(\mathrm{W}_{\mathrm{n}, \mathrm{i}}\right)$, being the work delivered to the piston during the induction, compression, expansion and exhaust strokes.

$$
\mathrm{W}_{\mathrm{n} 2 \mathrm{~s}, \mathrm{i}}=\int_{0}^{360} P d V \text { and } \mathrm{W}_{\mathrm{n} 4 \mathrm{~s}, \mathrm{i}}=\int_{0}^{720} P d V
$$

Where,

$\mathrm{W}_{\mathrm{n} 2 \mathrm{~s}, \mathrm{i}}=$ Net Indicated Work for a 2 -stroke cycle

$\mathrm{W}_{\mathrm{n} 4 \mathrm{s,i}}=$ Net Indicated Work for a 4-stroke cycle

Pumping Indicated Work $\left(\mathrm{W}_{\mathrm{p}, \mathrm{i}}\right)$ is the difference between the Gross Indicated Work and Net indicated Work.
Pumping indicated work $\left(\mathrm{W}_{\mathrm{p}, \mathrm{i}}\right)=$ Net indicated work $\left(\mathrm{W}_{\mathrm{n}, \mathrm{i}}\right)$ - Gross indicated work $\left(\mathrm{W}_{\mathrm{g}, \mathrm{i}}\right)$

\subsubsection{Calculation of Indicated Mean Effective Pressure (IMEP)}

The division of the gross indicated work per cycle by the engine's swept volume gives the Gross Indicated Mean Effective Pressure while the Net Indicated Mean Effective Pressure is obtained by dividing the Net Indicated Work per cycle by its effective engine volume. The difference between the gross (GMEP) and Net Mean Effective Pressure per cycle (NMEP) gives the Pumping Mean Effective Pressure (PMEP) as shown in the equations below.

Gross Mean Effective Pressure was used for all the calculations that involved Indicated Mean Effective Pressure (IMEP).IMEP $=\frac{W_{g, i}}{V_{s}}$

Where,

$V_{s}$ is the swept volume of the engine cylinder at the inlet port closure (IPC), since the exhaust port closes before the engine in LUPOE.

Chang (2002) calculated the IMEP of an engine fuelled with natural gas thus:

$$
\mathrm{IMEP}=\frac{\Delta \theta}{V_{s}} \sum_{i=\theta_{0}}^{\theta_{n}} P(i) \frac{d V}{d \theta}
$$

Where,

$V_{s}$ is the swept volume of the engine cylinder $\left(\mathrm{m}^{3}\right)$,

$\Delta \theta$ range of engine crank angle,

$V$ is the corresponding engine volume at an engine crank angle,

$P(i)$ is the corresponding engine pressure at an engine crank angle,

$\theta_{0}$ is the BDC induction crank angle position

$\theta_{n}$ is the BDC exhaust crank angle position

\subsubsection{Cycle -To-Cycle Variation}

During combustion in internal combustion engines, specifically in reciprocating engines; variation of the pressure trace curves, magnitude of peak pressures and the crank angle of the cycle peak pressure occurrence are observed from one cycle to the other. The variations from cycle-to-cycle in combustion processes limits the range of lean equivalence ratio, which could be used to achieve low emission, low fuel consumption, appropriate or required engine drivability required, power output and the overall improvement in engine efficiency (Curto-Risso et al., 2013). The non-repeatability of instantaneous combustion rate between different cycles at nominally identical operating condition has been identified as a limiting factor in determining the performance of an engine (Aghdam et al., 2007). This is known as cycle-to-cycle variation.

\subsubsection{Mass Fraction Burn}

Mass fraction burned is an important engine combustion parameter which reflects an engine performance. It shows the amount of fuel burned against crank angle during combustion duration in an engine (Shayler and Wiseman, 1990). The variation of the fuel mass burned expressed as a percentage of the total mass of fuel burned during the combustion cycle 
gives a direct indication of the quality of combustion. The mass fraction of fuel burned can be obtained through different existing models.

Over the years, mass fraction burned has been calculated or estimated with filmed flame images, from optical accessed research engines and bombs, the Vibe (Wiebe) function, the Rassweiler and Withrow method, the Matekunas pressure ratio method and the cosine burn-rate formula (Klein (2004), Brown (2009), Heywood (1988) Ferguson (1986) and Chang (2002)).

\subsection{ENGINE PERFORMANCE}

The performance of an engine can be evaluated using various engine performance parameters. These parameters include: (i) indicated power (ip) (ii) brake power (bp) (iii) friction power (fp) (iv) indicated and brake mean effective pressures (mep) (v) mechanical and thermal efficiencies (vi) fuel consumption (specific fuel consumption) (vii) volumetric efficiency.

\subsubsection{Indicated Power}

Indicated power can be defined as the rate of work done by the combusting charge on the piston as evaluated from the indicator diagram obtained from the engine. If the crosssectional area of a piston is given as $\mathrm{A}$ and the expanding combusting charge in the engine cylinder exerts a pressure $\mathrm{P}$ on the piston's cross sectional area A, the total force exerted on the piston is given as: Force $\mathrm{F}=\mathrm{P} . \mathrm{A}(\mathrm{N})$.

Assuming the pressure exerted on the piston remains constant and the piston is forced through a distance $\mathrm{L}$ which is equal to 1 meter.

The work done $\mathrm{W}=\mathrm{FL}=\mathrm{PaL}$.

If the piston makes $\mathrm{n}$ working strokes per second, then the work done per second is given as:

Power Developed $=$ PLAn $(\mathrm{W})$

In real engine operation, the engine cylinder pressure is not constant throughout the cycle. The mean effective pressure of the engine cylinder is calculated and used as P. The power calculated from the in-cylinder engine pressure is called the indicated power.

Indicated Power $(\mathrm{ip})=$ PLAn $(\mathrm{W})$ or PLAn $* 10^{-3}(\mathrm{KW})$.

The number of firing strokes per second in an engine is expressed as $\mathrm{n}$ while $\mathrm{N}$ represents the engine speed per second.

For a two-stroke engine $\mathrm{n}=\mathrm{N}$

For a four-stroke engine $n=N / 2$

For a double acting engine $n=2 N$

\subsubsection{Brake Power}

The power available at the piston is the indicated power and it is measured by the indicator diagram. The useful power finally generated by the engine (available to the crankshaft) is lower than the indicated power because of the power used to overcome friction at the bearings and sliding parts.

The power output of the engine available to the engine crankshaft is known as the brake power or shaftpower. It is called brake power because it is measured by a brake at the crankshaft.

Brake power $\mathrm{P}_{\mathrm{b}}=2 \pi \mathrm{NT}=\mathrm{T} \omega$ (Watts)

Where;

$$
\mathrm{T}=\mathrm{Fr} \text { and } \omega=2 \pi \mathrm{N}
$$

The difference between the indicated power and brake power is known as the friction power of the engine.

Friction Power $\mathrm{P}_{\mathrm{f}}=\mathrm{P}_{\mathrm{i}}-\mathrm{P}_{\mathrm{b}}$

Where,

$\mathrm{T}$ is the engine torque, $\mathrm{F}$ is engine load, $\omega$ is the engine speed (rpm), $r$ is radius and $P_{i}$ is the indicated power

\subsubsection{Mechanical Efficiency}

The mechanical efficiency of an engine is defined as the ratio of the power available to the crankshaft to the power available at the piston i.e. the ratio of engine brake power to the indicated power.

Mechanical Efficiency $\eta_{t h}=\frac{b p}{i p}$

\subsection{DATA ANALYSIS}

Engine torque and brake power data were obtained from a single cylinder four-stoke spark ignition engine test bed were was run on gasoline fuel and a blend of gasoline and biofuel blend. The data were obtained at various engine speeds and were processed based on the following procedures:

$>$ The mean of the results obtained with sample sizes of 20, 40, 60 and 100 cycles were processed and compared at various engine speeds, for part and full load conditions.

$>$ The percentage difference of the results calculated at various sample sizes were determined by calculating the percentage difference between results obtained with sample sizes of 20, 40 and 60 with results obtained with 100 sample sizes at the various engine speeds considered.

Percentage Difference (PD) (\%) $=\frac{X_{\max }-X_{s}}{X_{\max }} \times 100 \%$

Mean Percentage Difference $(\%)=\frac{\sum(P D)}{n}$

Where,

$\mathrm{X}_{\max }$ is the maximum available sample size, $\mathrm{X}_{\mathrm{s}}$ is the selected sample size and $\mathrm{n}$ is the number of values.

\subsection{RESULTS AND DISCUSSION}

The effect of sample size on the values of the combustion parameters determined was determined. The graphs in figures 1 and 2, show the plots of the engine's brake power and torque respectively, using sample sizes of 20, 40, 60 and 100 for the engine test done with gasoline and gasoline with various degrees of bio-fuel blends. The values were seen to be highest for all engine speeds, for calculations done with 20 samples for brake power and torque determination.

As the sample size increased, slight reduction on the values of the parameters determined were observed with variation between sample sizes reducing with higher values of sample sizes $(40,60,100)$. The percentage difference in values of determined parameters relative to 100 sample size values are shown in figures 3 and 4 for brake power and torque respectively. 
(a)

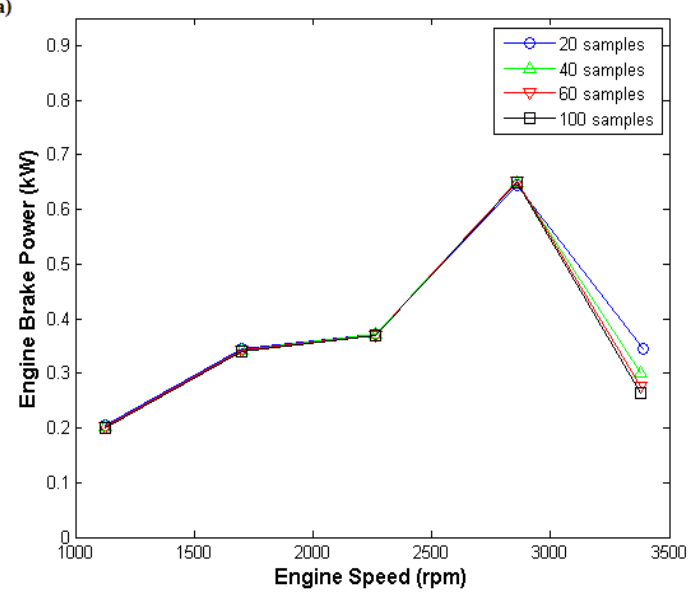

(b)

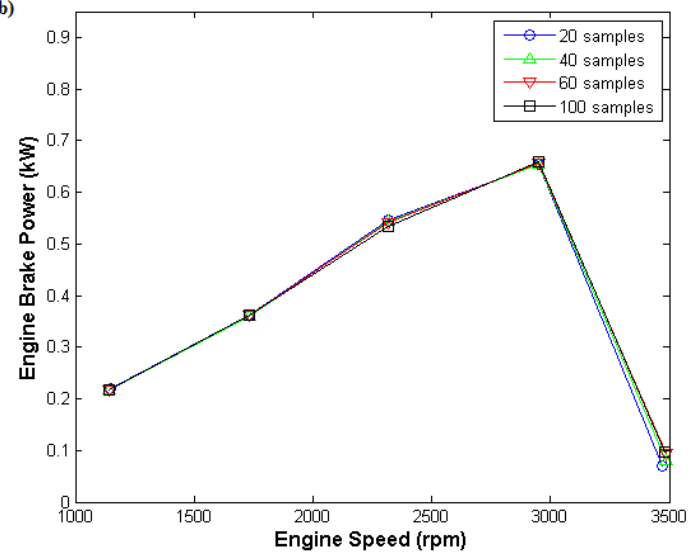

(c)

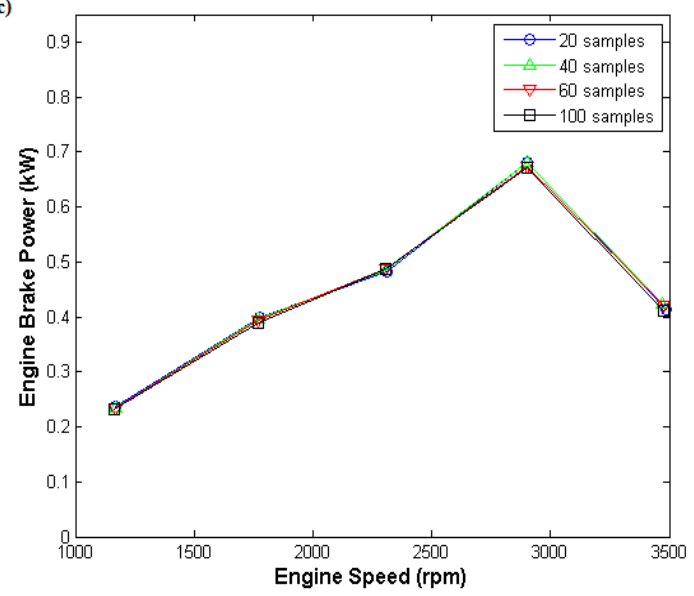

Figure 1: Calculated Brake Power using Varying Sample Sizes for (a) Gasoline (b) Gasoline with 1\% biofuel blend and (c) Gasoline with $5 \%$ biofuel blend

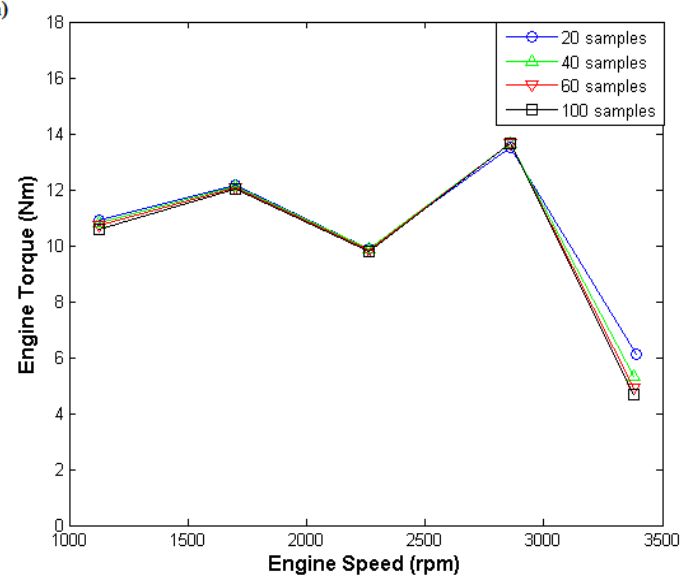

(b)

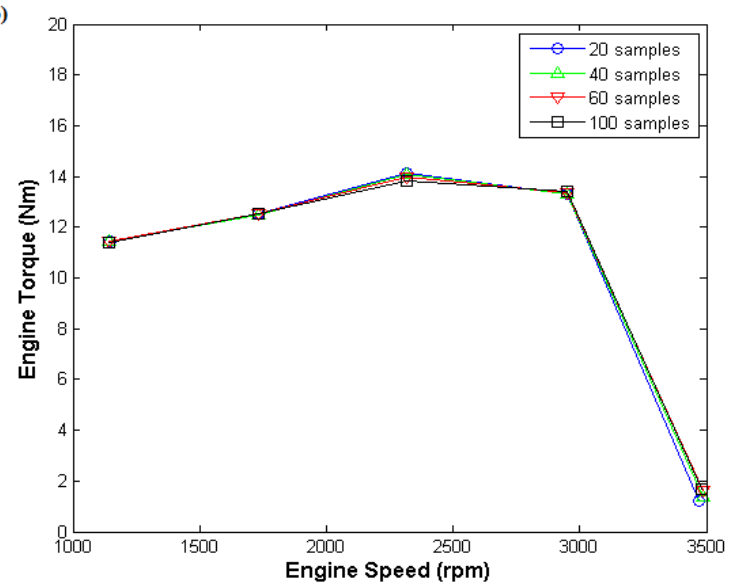

(c)

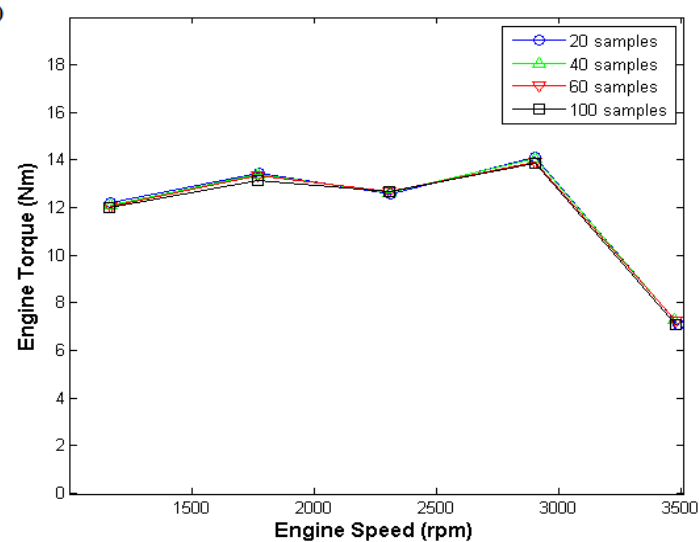

Figure 2: Calculated Engine Torque using Varying Sample Sizes for (a) Gasoline (b) Gasoline with $1 \%$ biofuel blend and (c) Gasoline with $5 \%$ biofuel blend 
(a)

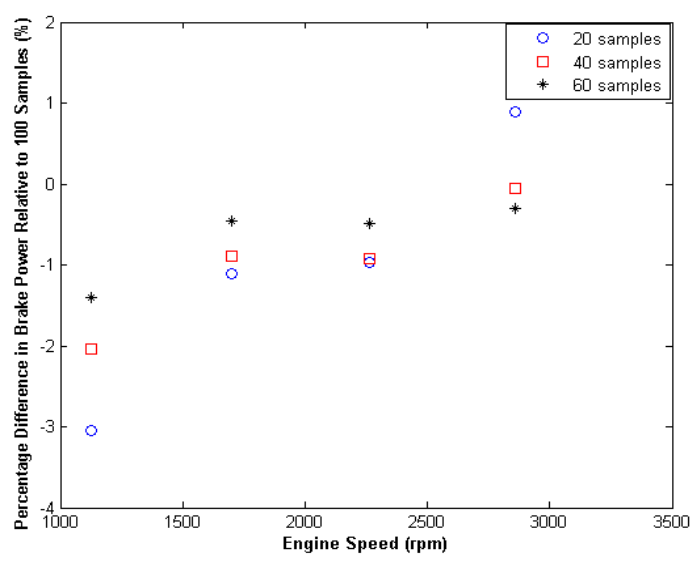

(b)

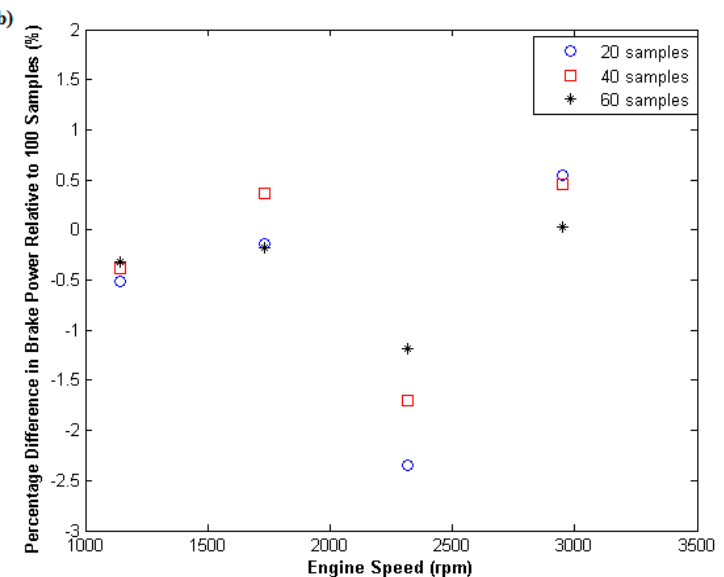

(c)

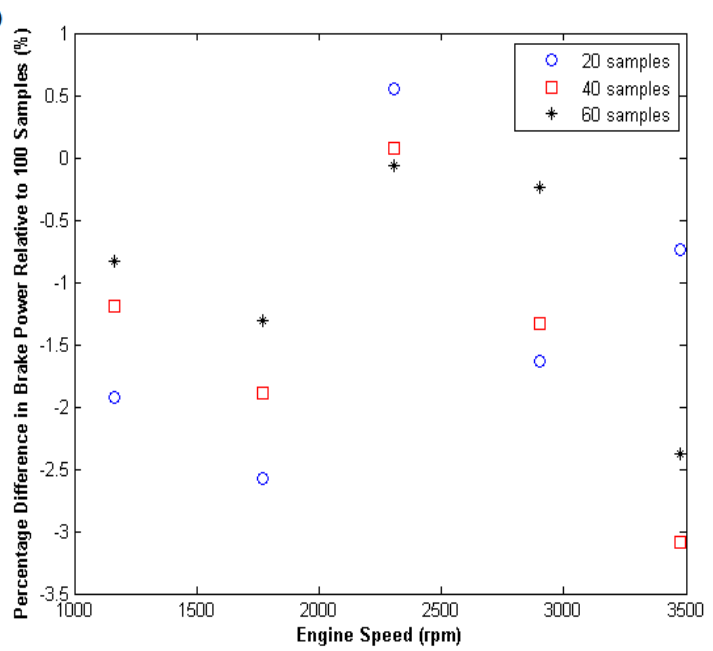

Figure 3: Percentage difference in brake power value relative to 100 samples (a) Gasoline (b) Gasoline with $1 \%$ biofuel blend and (c) Gasoline with $5 \%$ biofuel blend. (a)

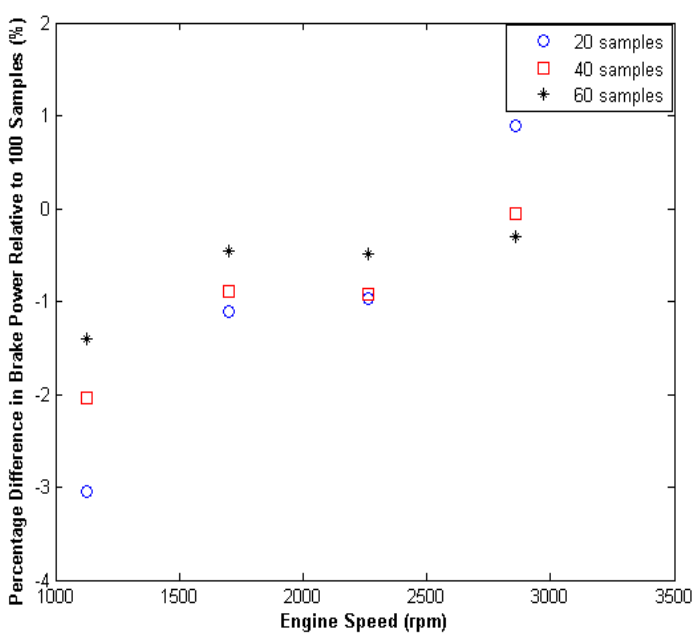

(b)

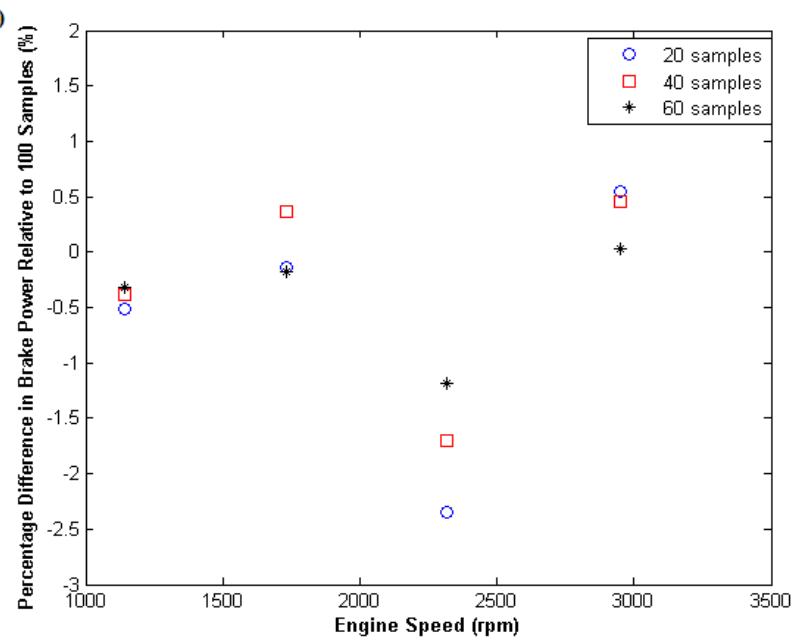

(c)

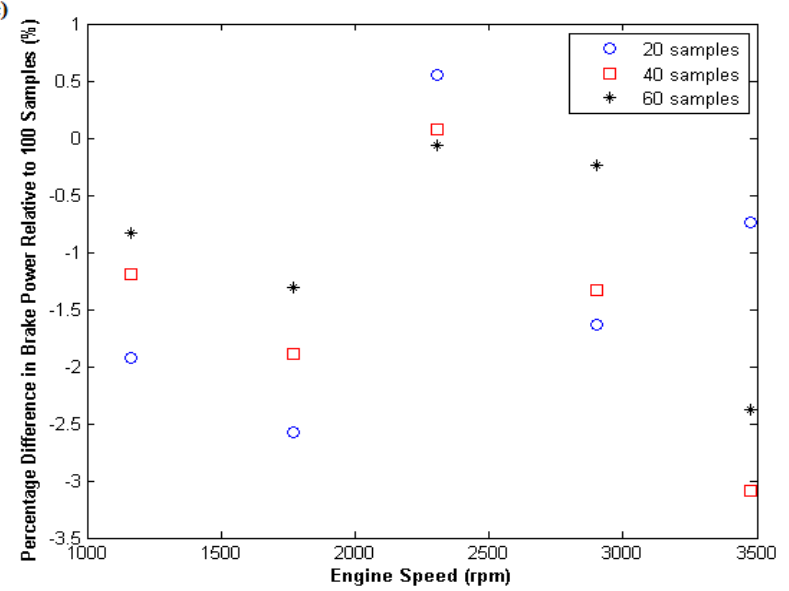

Figure 4: Percentage difference in brake power value relative to 100 samples (a) Gasoline (b) Gasoline with 1\% biofuel blend and (c) Gasoline with $5 \%$ biofuel blend. 
From figures 3 and 4 for the data from the three fuels tested, the percentage difference in parameter value at varying sample sizes used for the calculation, relative to 100 sample size, for brake power and engine torque are shown respectively.

The percentage difference in the values obtained with sample sizes of 20,40 and 60 , for engine brake power determination, ranged from -3.0 to $0.89 \%,-2.0$ to $-0.05 \%$ and 1.4 to $-0.3 \%$ for gasoline respectively. For gasoline with $1 \%$ biofuel, for sample sizes of 20,40 and 60 ranged from -2.3 to $0.55 \%,-1.7$ to $0.46 \%$ and -1.19 to $0.025 \%$ respectively. For gasoline with $5 \%$ bio-fuel, for sample sizes of 20,40 and 60 ranged from -1.9 to $0.55 \%,-3.09$ to $0.08 \%$ and -2.3 to $-0.07 \%$ respectively. For gasoline, the mean percentage difference for sample sizes of 20,40 and 60 were $-1.06,-0.98$ and $-0.66 \%$ respectively. For gasoline with $1 \%$ biofuel blend, $-0.61,-0.32$ and $-0.42 \%$ respectively while for gasoline with $5 \%$ biofuel, the values were $-1.27 \%,-1.49 \%$ and $-0.96 \%$.

The percentage difference in the values obtained with sample sizes of 20,40 and 60 , for engine torque determination, ranged from -2.98 to $0.92 \%,-1.99$ to $-0.02 \%$ and -1.37 to $0.26 \%$ for gasoline respectively. For gasoline with $1 \%$ bio-fuel, for sample sizes of 20, 40 and 60 the values ranged from -2.28 to $0.66 \%,-1.64$ to $0.61 \%$ and -1.17 to $0.11 \%$ respectively while for gasoline with $5 \%$ bio-fuel, for sample sizes of 20,40 and 60 the values ranged from -2.34 to $0.75 \%,-3.18$ to $0.16 \%$ and -2.26 to $0.05 \%$ respectively. For gasoline, the mean percentage difference for sample sizes of 20,40 and 60 were $-1.04,-0.95$ and $-0.64 \%$ respectively. For gasoline with $1 \%$ bio-fuel, the mean percentage difference values were $-0.52,-0.25$ and $-0.38 \%$ respectively while for gasoline with $5 \%$ bio-fuel, the mean percentage difference values were $-1.05,-1.43$ and $-0.89 \%$ respectively.

\subsection{CONCLUSION}

Combustion analysis was carried out to determine the effect of sample size on the values of engine parameters, with focus on the engine brake power and engine torque.

For the analysis, sample sizes of 20,40,60 and 100 were used and the values obtain from each sample size was compared with the values obtained with 100 sample size, to determine the difference. Much difference in determined values was not observed as seen in the engine parameter value plots and in the percentage difference. This makes the sample sizes tested appropriate for use. The percentage differences of the parameters determined were in the range of $\pm 3.2 \%$ while the mean of the values was in the range of $\pm 1.43 \%$.

To select the sample size to be used for combustion analysis, a test is to be done on the determination of the percentage difference from possible sample sizes to the maximum possible sample size to be used. If the mean percentage difference of the sample size selected, for an engine parameter to be tested is within the range of $\pm 1.5 \%$, the smallest sample size can be used for engine performance analysis.

This will lead to a shorter processing time and storage

\section{REFERENCES}

i. Aghdam E. A, Burluka A. A., Hattrell T., Liu K. and Sheppard G. W. (2007). Study of cyclic variation in an SI engine using quasidimensional combustion model. SAE Technical paper series, 2007 world congress Detroit, Michigan, April 16-19, 2007.

ii. Brown N. M. (2009) Characterisation of emissions and combustion stability of a port fuelled spark ignition engine, University of Nottingham, PhD thesis.

iii. Brunt, M.F.J. and Emtage, A.L. (1996) Evaluation of IMEP routines and analysis errors. SAE 960609. pp. 87-101.

iv. Cartwright, A. and Fleck, R., Cylinder pressure analysis in high performance two-stroke engines. SAE 962535, 1996. v. 105.

v. Chang W. (2002) An Improved Method of Investigation of Combustion Parameters in a Natural Gas Fuelled SI Engine with EGR and $\mathrm{H}_{2}$ as Additives, PhD thesis. School of Manufacturing and Mechanical Engineering. University of Birmingham, UK. pp 1-179.

vi. Cheung, H.M. and Heywood, J.B. (1993) Evaluation of a one zone burn-rate analysis procedure using production SI engine pressure data. SAE 932749. pp. 2292-2303.

vii. Chun, K.M. and Heywood, J.B. (1987) Estimating heatrelease and mass-of-mixture burned from spark-ignition engine pressure data. Combustion Science and Technology, v. 54: pp. 133-143.

viii. Conway Graham T. (2013) Cyclic Variability of Flame Propagation and Autoignition in Supercharged and Naturally Aspirated SI Engines. PhD Thesis. School of Mechanical Engineering. University of Leeds, UK.

ix. Curto-Risso P. L., Medina A., Calvo-Hernández A., GuzmánVargas L. and Angulo-Brown F. (2013) Fluctuations in the energetic properties of a spark-ignition engine model with variability. Entropy 15: 3277-3296. doi: 10.3390/e15083367.

x. Ferguson, C.R. (1986) Internal Combustion Engines, Wiley

xi. Gatowski, J.A., et al. (1984) Heat release analysis of engine pressure data. SAE 841359, pp. 961-977.

xii. Hassaneen, A.E., et al.( 1998) A study of the flame development and rapid burn durations in a lean burn, fuel-injected natural gas S.I. engine. SAE 981384, v. SP-1371.

xiii. Hayes, I.K., Savage, L.D., and Sorenson, S.C. (1986) Cylinder pressure data acquisition and heat release analysis on a personal computer. SAE 860029.

xiv. Heywood J. B., (1988) Internal Combustion Engine Fundamentals, McGraw-Hill Series in Mechanical Engineering, New York, United States 1- 930.

xv. Hussin, A. (2012) New and Renewable Energy: Renewable Fuels in Internal Combustion Engines. PhD Thesis. School of Mechanical Engineering. University of Leeds, UK.

xvi. Jensen, T.K. and Schramm, J.(2000) A three-zone heat release model for combustion analysis in a natural gas SI engine - effects of crevices and cyclic variations on UHC emissions. SAE 2000-01-2802.

xvii. Klein Marcus 2004. A specific heat ratio model and compression ratio estimation. PhD Thesis. Department of Electrical Engineering. Linköping University, Sweden.

xviii. Lancaster, D.R., Krieger, R.B., and Lienesch, J.H. (1975) Measurement and analysis of engine pressure data. SAE 750026. xix. Shayler P. J. and Wisernan M. W. (1990) Improving the Determination of Mass Fraction Burnt, SAE Technical Paper, 900351: $1-10$.

space. 